\title{
The Effect of Gastric Helicobacter pylori Eradication on the Clinical Course of Recurrent Aphthous Stomatitis- A Systematic Review
}

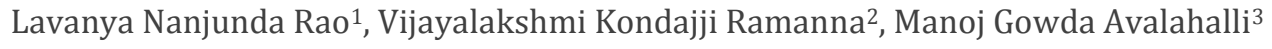 \\ ${ }^{1}$ Department of Oral Medicine and Radiology, Government Dental College and Research Institute, Bangalore, \\ Karnataka, India. ${ }^{2}$ Department of Oral Medicine and Radiology, Government Dental College and Research Institute, \\ Bangalore, Karnataka, India. ${ }^{3}$ Department of Medical Gastroenterology, Vydehi Institute of Medical Sciences and \\ Research Centre, Bangalore, Karnataka, India.
}

\section{ABSTRACT}

\section{BACKGROUND}

Recurrent aphthous stomatitis (RAS) is the most common ulcerative disorder of oral mucosa. The etiopathogenesis of RAS is multifactorial; however, recent studies have proposed Helicobacter pylori (H. pylori) as one of the causative factors. Helicobacter pylori is a known pathogen causing upper gastrointestinal symptoms and gastric ulcers. Oral cavity is one of the extra gastric reservoirs and a causative factor for reinfection which further requires eradication therapy. The aim of this systematic review was to retrieve clinical studies investigating the effect on the clinical course of recurrent aphthous stomatitis through gastric Helicobacter pylori eradication.

\section{METHODS}

Literature was searched in electronic search engines from 1997 to 2017. The identified titles/abstracts were independently screened according to the set criteria for selection of abstracts. 6 full text articles were selected and assessed for eligibility.

\section{RESULTS}

All the studies evaluated the subjects with recurrent aphthous stomatitis for the Helicobacter pylori and the positive ones were given $H$. pylori eradication therapy and were followed up for certain period of time for the recurrence rate, amelioration time, number of lesions, frequency and intensity of the symptoms. Subjects who underwent $H$. pylori eradication therapy, decrease in the symptoms of recurrent aphthous stomatitis was noted.

\section{CONCLUSIONS}

This systematic review indicates that eradication of $H$. pylori can be effective in the management of recurrent aphthous stomatitis.

\section{Corresponding Author:} Dr. Lavanya Nanjunda Rao, Room No. 1, Department of Oral Medicine and Radiology, Government Dental College and Research Institute, Victoria Hospital Campus, Bangalore-560002, Karnataka, India.

E-mail: lavanyanvavhale@gmail.com

DOI: $10.14260 / j e m d s / 2019 / 768$

Financial or Other Competing Interests: None.

How to Cite This Article: Rao LN, Ramanna VK, Avalahalli MG. The effect of gastric helicobacter pylori eradication on the clinical course of recurrent aphthous stomatitis- a systematic review. J. Evolution Med. Dent. Sci. 2019;8(47):3554-3559, DOI: $10.14260 /$ jemds/2019/768

Submission 25-09-2019, Peer Review 08-11-2019, Acceptance 15-11-2019, Published 25-11-2019.

\section{KEY WORDS}

Helicobacter pylori, Aphthous Stomatitis 


\section{BACKGROUND}

Aphthai was first termed by Hippocrates (460-370 BC) who used this term to describe the disorders of the mouth. Recurrent aphthous stomatitis (RAS, aphthae) is poorly understood yet most common mucosal disorder which is characterized by varying sizes, solitary or multiple in number, round or ovoid in shape, recurrent in nature, circumscribed margins surrounded by erythematous haloes with yellow or gray floors. 1,2

This mucosal disorder affects $25 \%$ of world population with the point prevalence of $4 \%$, which might continue throughout the life span with the peak age of onset between 10 and 19 years. ${ }^{3}$ These ulcers are characterized by significant pain which is disproportionate to the size of the ulcers which usually heals within 10-21 days. Though it is of short duration, it has a negative impact on the patient's quality of life presenting as a public health burden, irrespective of its aetiology.4,5

Although the aetiology is multifactorial, local and systemic factors have been suggested to affect the development of RAS. Some of the predisposing factors include trauma, hormonal changes, diet, nutritional deficiencies, Celiac disease, and immunological disorders and genetic polymorphisms. ${ }^{6}$ Most of studies has been conducted to investigate the role of various microorganisms which includes Bacterial (Streptococci, Helicobacter pylori, Lactobacillus) Viral (Varicella zoster, Cytomegalovirus) in the aetiopathogenesis of RAS, and few of the studies has depicted the possible involvement of Helicobacter pylori infection in subjects with recurrent aphthous stomatitis (RAS), but however this association still remains debatable. ${ }^{7}$

H. pylori is a gram negative, spiral, microaerophilic microorganism that infects more than $50 \%$ of human gastric mucosa. ${ }^{7}$ In India, it has a high prevalence of $49.94 \%-83.30 \%$ due to the low socioeconomic status, poor hygiene, inadequate sanitation conditions, overcrowding, consumption of contaminated water and food, and bacterial infection within the household. ${ }^{8}$ H. pylori has been strongly associated and has been proven with various diseases such as peptic ulcer disease, mucosa-associated lymphoid tissue lymphoma, chronic superficial gastritis and gastric adenocarcinoma.7,9

The association between RAS and $H$. pylori infection has been supported due to the histological similarity between RAS and peptic ulcers. $H$. pylori causes ulceration by producing heat shock proteins, lymphocyte chemotactic factors leading to neutrophilic infiltration thereby causing mucosal injury. ${ }^{7}$ The eradication of $H$. pylori involves antibiotic regimens- which includes bismuth quadruple therapy, clarithromycin-based therapy, levofloxacin-based therapy. Few of the investigators have noted that eradication of gastric Helicobacter pylori affected the clinical course of recurrent aphthous stomatitis. ${ }^{6}$ Various articles investigating the effect of $H$. pylori eradication in recurrent aphthous stomatitis were systematically reviewed.

\section{Aim}

The present systematic review was conducted to evaluate the effect of Helicobacter pylori eradication on the clinical course of the patients with recurrent aphthous stomatitis on the basis of the related literature and the evidences.

\section{METHODS}

\section{Study Question}

This study evaluated the outcome of literature in the eradication of gastric $H$. pylori and its impact on the clinical course of recurrent aphthous stomatitis.

\section{Review Design}

The present systematic review was carried out by three investigators with an aim to systematically retrieve and analyse clinical studies investigating the eradication of Helicobacter pylori in patients with recurrent aphthous stomatitis. The first investigator performed an electronic search. Thus, identified titles/ abstracts through the search engines were independently screened by first the investigators according to set inclusion and exclusion criteria for selection of abstracts. Full text articles of the selected abstracts were retrieved by the first investigator and further retrieval of titles/ abstracts was done by cross - referencing of full text articles. The full text articles were assessed for the eligibility by the investigators and the selected studies are assessed for the quality of their reporting with set selection criteria.

\section{Search Strategy}

An electronic data base search was performed in Pub Med and Science Direct for last 20 years from a time period of January 1997 to June 2017. The MESH keywords were ("Helicobacter pylori" [MeSH Terms] or ("Helicobacter" [All Fields] and "pylori" [All Fields]) or "Helicobacter pylori" [All Fields]) and ("Stomatitis" [MeSH Terms] or "stomatitis" [All Fields]).

\section{Results of the Search}

There were 415 papers which were identified from the electronic databases (January 1997 to June 2017) using the search strategy. All the records obtained were screened according to the title, keywords and abstracts. 389 papers articles did not meet the inclusion criteria hence they were excluded, 26 papers were found eligible and full text of these articles were extracted for further assessment.

From these, 11 articles were assessed, and references were studied for additional relevant studies and six studies were confirmed, however, since all these were already included in the original search, no additional studies were included.

\section{Excluded Studies}

From the 26 papers describing the possible association, 15 articles were excluded out of which one was a review, and remaining 14 articles did not consider the association between $H$. pylori and Aphthous stomatitis. Out of 11 papers which described the association of $H$. pylori infection and recurrent aphthous stomatitis, 5 papers were excluded because of insufficient data.

\section{Included Studies}

Six studies were finalized, and all the studies were published between 2005 and 2017. Finally, six full text articles were selected and assessed for eligibility through PICO guidelines. Agreement concerning study inclusion or exclusion was 
achieved by thorough discussion among the investigators. 6 full- text articles were evaluated with participants, interventions, comparators, outcomes (PICO) guidelines ${ }^{10}$ as follows-

\section{Participants}

Studies involved participants, who were diagnosed to have recurrent aphthous stomatitis clinically.

\section{Type of Interventions}

H. pylori eradication therapy- Two antibiotics and one proton pump inhibitors.

Comparators (Control)- No H. Pylori eradication

\section{Primary Outcomes Assessed}

Pain which is associated with RAS; duration of each episode associated with RAS; frequency of the episode associated with RAS; details of the intervention with its adverse effects.

\section{Secondary Outcomes Assessed}

Secondary outcomes which were assessed were any improvement in the patients' quality of life, morbidity level (e.g. function).

\section{Data Extraction and Synthesis}

Data of the 6 full - text articles was extracted and recorded in a format designed for this purpose. The data extracted from all the studies were combined and the subjects who were administered $H$. pylori eradication therapy were considered into interventional group. Subjects who were negative to $H$. pylori were considered in control group. The data of the 6 full - text articles were assessed for eligibility according to PICO guidelines and included in the systematic review. The extracted data resulted in 151 subjects who were administered $H$. pylori eradication therapy were considered to be in interventional group in the systematic review. 45 subjects were considered in the control/ comparator group. Out of which, 30 were on no treatment group, 15 were on tetracycline mouthwash.

\begin{tabular}{|ll|}
\hline Inclusion Criteria- \\
\hline $1 . \quad \begin{array}{l}\text { Case control, prospective study which mention the use of h pylori eradication } \\
\text { therapy for management of recurrent aphthous stomatitis on human } \\
\text { subjects. } \\
\text { Case control, prospective study in the management of RAS which include a } \\
\text { group intervened with } H . \text { pylori eradication therapy. }\end{array}$ \\
$\begin{array}{ll}\text { Case control, prospective study in which effect of h pylori eradication on the } \\
\text { clinical course of the RAS could be clearly/ separately identified. }\end{array}$ \\
\hline Exclusion Criteria- \\
\hline $\begin{array}{l}\text { Publications which are of other languages other English. } \\
\text { Review articles on management of recurrent aphthous stomatitis. }\end{array}$ \\
\hline \\
Table 1. Inclusion and Exclusion Criteria Used for Screening of \\
Title/ Abstracts
\end{tabular}

\section{RESULTS}

\section{Study Characteristics}

The electronic searches yielded a total of 415 articles, following a meticulous search strategy according to Prisma guidelines (Fig. 1), finally 6 full text articles were selected and assessed for eligibility through PICO guidelines. The designs of the studies were prospective and case-control study. All studies were systematically appraised.
The data were extracted and stratified. All the 6 included studies assessed eradication of gastric $H$. pylori and its impact on the clinical course of recurrent aphthous stomatitis. All the studies evaluated the $H$. pylori in patients with recurrent aphthous stomatitis and the positive ones were given $H$. pylori eradication therapy and were followed up for certain period for the recurrence rate, amelioration time, number of lesions, frequency and intensity of the symptoms.

\section{Characteristics of Outcomes}

- Decrease in recurrence rate was assessed in the study Farmaki et al, Karaca et al, Tsiloni et al.

- Decrease in the frequency and intensity of symptoms was assessed by Farmaki et al.

- Reduction in the number of lesions was seen by Arslan et al and Shereen et al.

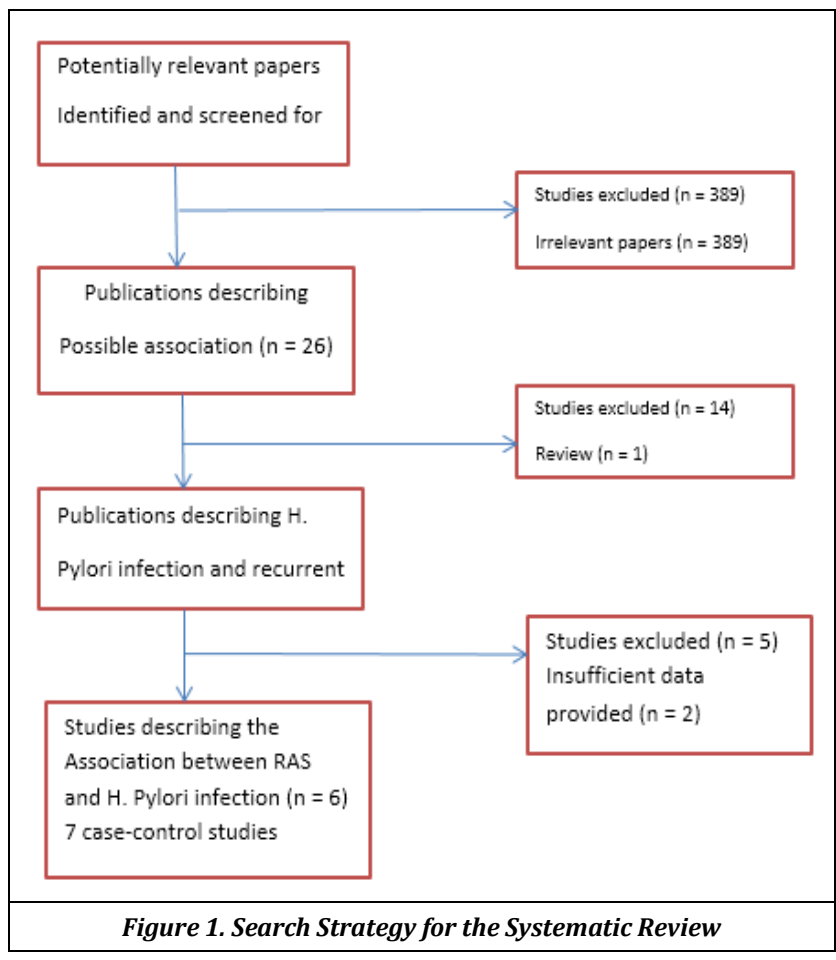

\begin{tabular}{|c|c|c|c|c|c|}
\hline 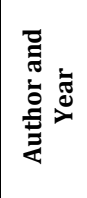 & : & 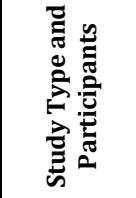 & 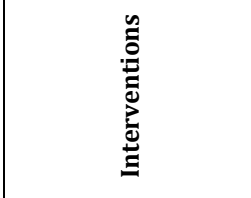 & 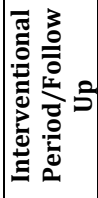 & 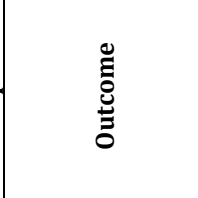 \\
\hline 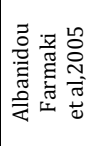 & 巡 & $\begin{array}{l}\text { Case control } \\
\quad \text { study } \\
\text { Group 1 - 34 } \\
\text { Group 2-14 }\end{array}$ & $\begin{array}{c}\text { Omeprazole } 20 \mathrm{mg} \text { B.I.D. } \\
\text { Clarithromycin } 500 \mathrm{mg} \\
\text { bid Amoxicillin } 1000 \mathrm{mg} \\
\text { bid for } 7 \text { days }\end{array}$ & 굴 & $\begin{array}{l}\text { decrease in the } \\
\text { frequency of } \\
\text { recurrence and the } \\
\text { intensity of } \\
\text { symptoms }\end{array}$ \\
\hline 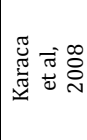 & 离 & $\begin{array}{l}\text { Prospective } \\
\text { study } \\
\text { Subjects - } 23\end{array}$ & $\begin{array}{l}\text { Clarithromycin } 500 \mathrm{mg} \\
\text { B.I.D. and amoxicillin } \\
1000 \mathrm{mg} \text { B.I.D. for } 2 \\
\text { weeks omeprazole } 20 \mathrm{mg} \\
\text { B.I.D. for } 4 \text { weeks }\end{array}$ & 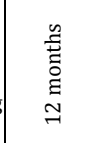 & $\begin{array}{l}\text { Decrease in the } \\
\text { recurrence rate and } \\
\text { amelioration time }\end{array}$ \\
\hline 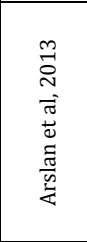 & 总 & $\begin{array}{l}\text { Case control } \\
\text { study } \\
\text { Group 1-30 } \\
\text { Group 2-16 }\end{array}$ & $\begin{array}{c}\text { Amoxicillin } 1000 \mathrm{mg} \\
\text { B.I.D. } \\
\text { Clarithromycin } 500 \mathrm{mg} \\
\text { B.I.D. } \\
\text { Lansoprazole } 30 \mathrm{mg} \\
\text { B.I.D. for } 14 \text { days } \\
\text { Additional lansoprazole } \\
30 \mathrm{mg} \text { B.I.D./O.D. for } 2 \\
\text { months }\end{array}$ & 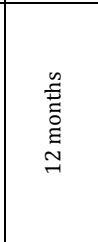 & $\begin{array}{l}\text { Reduction in } \\
\text { number of lesions }\end{array}$ \\
\hline
\end{tabular}




\begin{tabular}{|c|c|c|c|c|c|}
\hline 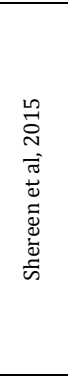 & 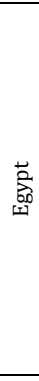 & $\begin{array}{l}\text { Case control } \\
\text { study } \\
\text { Group } 1-15 \\
\text { Group 2-15 } \\
\text { Group 3-15 }\end{array}$ & \begin{tabular}{|c|} 
Group $1-$ H. pylori \\
eradication* and \\
tetracycline mouthwash \\
Group $2-$ H. pylori \\
eradication therapy* \\
Group 3 - tetracycline \\
mouthwash only \\
*amoxicillin $1000 \mathrm{mg}$ \\
B.I.D. Clarithromycin 500 \\
mg B.I.D. \\
Proton pump inhibitor \\
20 mg B.I.D. \\
Colloidal bismuth \\
subcitrate Q.I.D. \\
\end{tabular} & 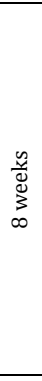 & $\begin{array}{l}\text { Group } 1 \text { and Group } \\
2 \text { were effective } \\
\text { in reducing the } \\
\text { number of lesions, } \\
\text { improving pain } \\
\text { relief and ulcer } \\
\text { healing which was } \\
\text { maintained } \\
\text { up to eight weeks } \\
\text { when compared to } \\
\text { Group } 3\end{array}$ \\
\hline 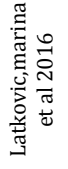 & 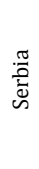 & $\begin{array}{l}\text { Pilot study } \\
\text { Subjects -15 }\end{array}$ & $\begin{array}{l}\text { Two antibiotics and one } \\
\text { proton pump } \\
\text { inhibitor }\end{array}$ & 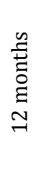 & $\begin{array}{c}\text { None of them } \\
\text { reported recurrence } \\
\text { of lesions }\end{array}$ \\
\hline 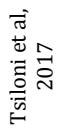 & 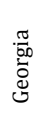 & $\begin{array}{l}\text { Prospective } \\
\text { study } \\
\text { Subjects- } 19\end{array}$ & $\begin{array}{l}\text { Helicobacter } \\
\text { eradication therapy }\end{array}$ & 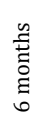 & $\begin{array}{c}\text { No recurrence of } \\
\text { lesions until follow } \\
\text { up period }\end{array}$ \\
\hline \multicolumn{6}{|c|}{$\begin{array}{l}\text { Table 2. Check List for Data Extraction Including the Year of } \\
\text { Publication, Country, Study Design, Sample Size, Interventions, } \\
\text { Interventional Period Detection and the Results of Each Study }\end{array}$} \\
\hline
\end{tabular}

\section{DISCUSSION}

H. pylori eradication has the impact on the clinical course of the recurrent aphthous stomatitis. Various studies have proved that $H$. pylori eradication is effective in decrease in recurrence rate and number of lesions of recurrent aphthous stomatitis. This systematic review aimed to assess the evidence of gastric eradication (Triple therapy) in management of signs and symptoms of recurrent aphthous stomatitis and to compare it with controls were $H$. pylori negative.In our systematic review, all the 6 included studies assessed eradication of gastric $H$. pylori and its impact on the clinical course of recurrent aphthous stomatitis. All the studies evaluated the $H$. pylori in patients with recurrent aphthous stomatitis and the positive ones were given $H$. pylori eradication therapy and were followed up for certain period for the recurrence rate, amelioration time, number of lesions, frequency and intensity of the symptoms. After a certain period of follow up decrease in frequency and intensity of the symptoms, recurrence rate of the lesions, decrease in number of the lesions and amelioration time was noted, showing it to be effective.

Previous systematic review done by $\mathrm{Li}$ et $\mathrm{al}^{7}$ aimed at different hypothesis, wherein the potential association between RAS and $H$. pylori infection by performing a quantitative meta-analysis of published case-control studies, found that the rate of $H$. pylori infection was greater in RAS patients than in non-RAS patients. They analysed 610 patients, which included 154 cases of $H$. pylori infection. They found that the rate of $H$. pylori infection was greater in RAS patients than in non-RAS patients, they concluded that $H$. pylori infection was associated with an increased risk of RAS.

Farmaki et al.,11 noted $33.3 \%$ decrease in both frequencies of recurrence and intensity of symptoms with $62.5 \%$ remarkable improvement after eradication therapy. The observation which was done in this study was that the subjects who were negative after eradication therapy were of comparable clinical status with those who were $H$. pylori negative from the beginning of the study. The possible explanation of how $H$. pylori and RAS is associated was quoted in this study, which is through the immune mediated mechanism, in which $\mathrm{H}$ Pylori strains has the ability to stimulate cytokine production - IL-8 and induces secretion of lymphocyte chemotactic factors with the formation of particular T lymphocytes subpopulations. Cytotoxins such as hydrogen peroxide and hypochlorous acid could be activated by the bacterium to produce reactive oxygen metabolites further infiltrating neutrophils. Though this study did not prove an aetiological relationship between $\mathrm{H}$ Pylori infection and RAS, it showed a strong correlation of patients $(62.5 \%)$ who demonstrated a complete or considerable remission of symptoms after $\mathrm{H}$ Pylori eradication treatment. They considered this result is prominent since RAS has a negative impact on the quality of life, and requires a range of interventions due its nature of recurrence. They concluded that there is a potential relationship between RAS and $\mathrm{H}$ Pylori.

According to Karaca et al.,12 There was statistically significant decrease in the recurrence rate and amelioration time of RAS by eradication therapy. There were no significant correlations among the intensity of $H$. pylori with the recurrence rate, number, diameter, and amelioration time of the lesions in 1-year follow-up. The explanation which was given for the controversial results of association of $H$. pylori with the RAS is, due to the methodological and technical differences which is used - such as micro - Culture, enzymelinked immunosorbent assay (ELISA), and polymerase chain reaction (PCR) with various modifications for isolation $H$. pylori. A significant correlation of gastric $H$. pylori existence (not density) and RAS was noted; they hypothesized that unknown products (antigens or superantigens?) of bacteria might act as a contributing factor towards RAS. These authors recommended the alternative adjuvant therapy in the treatment of RAS can be through the H. pylori eradication.

Arslan et $\mathrm{al}^{13}$ showed that mean number of aphthous lesions for the period of 6 months of $H$. pylori eradicated group was significantly decreased after eradication when compared with non-eradicated group. There was a negative correlation in total study group between the number of aphthous lesions and vitamin B12 levels. They speculated that vitamin B12 might have an aetiological effect on the aphthous lesions. They suggested that, eradication of $H$. pylori in RAS can decrease the symptoms by increase in the levels of vitamin B12. They emphasized the need for further studies to determine the $H$. pylori eradication mechanisms for improvement of RAS lesions.

As per Shereen et al,14 Group 1 and Group 2 (H. pylori eradication therapy) were effective in reducing the number of lesions, improving pain relief and ulcer healing which was maintained up to eight weeks when compared to Group 3. \{Group 1- H. pylori eradication* and tetracycline mouth wash, Group 2- H. pylori eradication therapy *Group 3- tetracycline mouthwash only\}.In this study, tetracycline mouthwash was added as a promising adjunct with $H$. pylori eradication therapy and significant results were found. The possible mechanism which was explained is that the mouthwash inhibits the collagenases and metalloproteinases of the inflammatory response that contributes to the tissue destruction and ulcer formation. It was concluded that $H$. pylori has a role in the development of RAS, and the 
frequency and severity of RAS lesion can be decreased through tetracycline mouthwash or improved oral hygiene measures which can improve the comfort and quality of life in these patients.

However, Latkovic, marina et $\mathrm{al}^{15}$ conducted a preliminary study of $H$. pylori eradication in patients with recurrent aphthous stomatitis without any gastric symptoms, in whom none of them recurrence of lesions until the follow up period. They concluded that the oral cavity can act as a reservoir for this micro-organism and its absence after its eradication can prove the possible connection of $H$. pylori with RAS.

Tsiloni et al,16 in their study of small sample size, reported no recurrence of lesions until the follow - up period. The results of this study showed the higher possibility of $H$. pylori in the etiopathogenesis of RAS. They emphasized that oral cavity can be a secondary reservoir for H. pylori and act as source of gastric reinfection for the various gastroduodenal pathologies. They also opined that H. Pylori has the potential to enhance aggressive factors and reduce mucous membrane protective factors.

As this strong correlation has been noted between $H$. pylori and recurrent aphthous stomatitis, $H$. pylori should be considered as one of the aetiological factors so that it can implicate towards its better management, improvement in lifestyle of the patients and better prognosis. The triple therapy has found to be effective to decrease the recurrence rate, amelioration time, number of lesions, frequency and intensity of the symptoms.

\section{Limitations}

This systematic review assessed the data of various studies which estimated the treatment effects which would be more precise than the single study. The limitation which we came across, as with any overview is that the treatment regimen used, and the outcome measures are not the similar and identical across all the studies. Characteristic outcome could not be assessed due to lack of consensus among researcher's invalidation of other signs and symptoms of RAS. At the study and review level our review did not include any grey literature and studies published in other languages were not considered in the review. Only 6 full - text article could be retrieved due to constrained resources available to the investigators.

\section{CONCLUSIONS}

\section{Implications for Practice}

Even though the investigators concluded that the gastric $H$. pylori eradication was found to be effective in decreasing symptoms and could be beneficial in the therapeutic management of recurrent aphthous stomatitis, it might still not be very reliable due to the limited amount of data available to support these contents.

\section{Implications for Research}

Recently, many studies have been conducted to investigate the role of $H$. pylori in the etiopathogenesis of recurrent aphthous stomatitis. But the treatment of RAS has been clearly inadequate owing to its multi-factorial pathogenesis and evaluation of the merits and disadvantages of each treatment modality has been difficult because of empirical nature of the approach. This systematic review opines that future research trials should be reported strictly adhering to the CONSORT guidelines to ensure high quality research especially in terms of randomization and blinding of the subjects for better results. However, this systematic review stresses the need of consensus among investigators so that significant evidence of a particular treatment modality like $H$. pylori eradication could be achieved in future review designs.

\section{REFERENCES}

[1] Chavan M, Jain H, Diwan N, et al. Recurrent aphthous stomatitis: a review. Journal of Oral Pathology \& Medicine 2012;41(8):577-83.

[2] Natah SS, Konttinen YT, Enattah NS, et al. Recurrent aphthous ulcers today: a review of the growing knowledge. International Journal of Oral and Maxillofacial Surgery 2004;33(3):221-34.

[3] Ship JA. Recurrent aphthous stomatitis: an update. Oral Surgery, Oral Medicine, Oral Pathology, Oral Radiology and Endodontics 1996;81(2):141-7.

[4] Patil S, Reddy SN, Maheshwari S, et al. Prevalence of recurrent aphthous ulceration in the Indian population. Journal of Clinical and Experimental Dentistry 2014;6(1):e36-40.

[5] Huling LB, Baccaglini L, Choquette L, et al. Effect of stressful life events on the onset and duration of recurrent aphthous stomatitis. Journal of Oral Pathology \& Medicine 2012;41(2):149-52.

[6] Gomes CC, Gomez RS, Zina LG, et al. Recurrent aphthous stomatitis and Helicobacter pylori. Medicina Oral, Patologia Oral Cirugia Bucal 2016;21(2):e187-91.

[7] Li L, Gu H, Zhang G. Association between recurrent aphthous stomatitis and Helicobacter pylori infection: a meta-analysis. Clinical Oral Investigations 2014;18(6):1553-60.

[8] Misra V, Pandey R, Misra SP, et al. Helicobacter pylori and gastric cancer: Indian enigma. World Journal of Gastroenterology 2014;20(6):1503-9.

[9] Rasmussen LT, Labio RW, Gatti LL, et al. Helicobacter pylori detection in gastric biopsies, saliva and dental plaque of Brazilian dyspeptic patients. Memorias do Instituto Oswaldo Cruz 2010;105(3):326-30.

[10] Da Costa SCM, De Mattos PCA, Nobre MR. The PICO strategy for the research question construction and evidence search. Revista Latino-Americana De Enfermagem 2007;15(3):508-11.

[11] Albanidou-Farmaki E, Giannoulis L, Markopoulos A, et al. Outcome following treatment for Helicobacter pylori in patients with recurrent aphthous stomatitis. Oral Diseases 2005;11(1):22-6.

[12] Karaca S, Seyhan M, Senol M, et al. The effect of gastric Helicobacter pylori eradication on recurrent aphthous stomatitis. International Journal of Dermatology 2008;47(6):615-7. 
[13] Tas DA, Yakar T, Sakalli H, et al. Impact of helicobacter pylori on the clinical course of recurrent aphthous stomatitis. Journal of Oral Pathology \& Medicine 2013;42(1):89-94.

[14] Shereen AA, Sahar MG, Wesam SI. Helicobacter pylori eradication: a promising adjunct treatment for aphthous stomatitis. Dental Journal 2015;61(1437):1449.
[15] Latković M, Ranin L, Teodorović N, et al. Eradication of Helicobacter pylori in patients without gastric symptoms suffering from recurrent aphthous stomatitis: a pilot study. Vojnosanitetski Pregled 2017;74(7):672-5.

[16] Tsilosani N, Khimshiashvili N, Salia S. Investigation of the role of Helicobacter pylori in the etiopathogenesis of current aphthous stomatitis. European Scientific Journal 2017:12(10). 